\title{
THIAMINE-DEFICIENT DIET IN TOURNIQUET SHOCK IN RATS ${ }^{1}$
}

\author{
BY LEONARD I. KATZIN AND STAFFORD L. WARREN \\ (From the Department of Radiology of the University of Rochester School of Medicine and Dentistry, \\ Rochester, $N . Y$.)
}

(Received for publication June 5, 1944)

\section{INTRODUCTION}

It has been reported (1) that body thiamine levels play a very important rôle in the resistance to hemorrhage shock in dogs. This report describes an attempt to confirm the rôle of thiamine in the case of tourniquet shock in rats. The tourniquet procedure has been well standardized (2). Using young adult rats under such a standardized procedure, it is possible to obtain a statistically valid analysis of the rôle of thiamine in tourniquet shock. While a comparison may or may not be made between two types of shock in two different species, we feel that these negative results are at least typical of tourniquet shock in rats.

\section{METHODS}

"Shock" was produced by placing a rubber-band tourniquet on one hind limb of a rat, leaving it for a stated period of time, and then removing the tourniquet. Upon removal, the animal goes into "shock," which under properly chosen conditions is fatal. The proportion of fatalities obtained is determined by the amount of tissue included under the tourniquet, the length of time the tourniquet is in position, and the environmental temperature, among other things. In these experiments, the tourniquet was applied to one hind limb only, usually anchoring it aver the head of the femur. This served both to standardize the location and to prevent the band from slipping down to a lower position. After preliminary experiments, a length of time during which the tourniquet was in position was chosen such that only a small proportion of the normal rats used would suffer a fatal outcome to shock. Under these circumstances, if the thiamine-depleted animals proved more susceptible to shock, they would show a definitely higher death rate.

Litters of young rats were divided into control and test groups. The controls were fed the standard laboratory diet containing adequate thiamine, the others were fed

1 The work described in this paper was done under a contract, recommended by the Committee on Medical Research, between the Office of Scientific Research and Development and the University of Rochester School of Medicine and Dentistry. Part of the work was also assisted by grants in aid from the Rockefeller Foundation and the Fluid Research Fund of the University of Rochester. the thiamine-deficient diet used by earlier workers (1): 18.6 per cent vitamin-free casein, $\mathbf{5 8 . 8}$ per cent sucrose, 7.8 per cent cottonseed oil, 3.9 per cent salt mixture, 7.8 per cent autoclaved yeast, 1.0 per cent agar, and 2.0 per cent cod-liver oil. Experiments were performed after various periods on this diet.

No tissue analyses for thiamine were made, nor was the autoclaved yeast analyzed. However, many observations clearly indicated dietary effects on the rats fed the synthetic diet. These animals lost their appetites to a large extent, lost weight, became irritable and timorous. Their coats became mussed and dirty-looking. One had no difficulty telling normally fed rats from those on the synthetic diet. In addition to feeding the synthetic diet, coprophagia was minimized by using cages with mesh floors, through which the fecal pellets dropped. An occasional surviving animal was offered the standard "dog chow" diet which it proceeded to attack ravenously.

No attempt was made to regulate the environmental temperature or other environmental factors, all controls being run simultaneously under the same laboratory conditions as the corresponding test group.

\section{RESULTS}

The results obtained are summarized in Table I. Of 24 animals, all survived a tourniquet in place for 4 to $4 \frac{1}{4}$ hours. Of 88 animals sub-

TABLE I

Effect of thiamine-deficient diet on tourniquet shock survival in young adult rats

\begin{tabular}{|c|c|c|c|c|c|}
\hline \multirow{2}{*}{$\begin{array}{c}\text { Tourniquet } \\
\text { duration }\end{array}$} & \multicolumn{2}{|c|}{ Controls } & \multicolumn{3}{|c|}{$B_{1}$-deficients } \\
\hline & $\begin{array}{c}\text { Number } \\
\text { of } \\
\text { rats }\end{array}$ & $\begin{array}{c}\text { Number } \\
\text { suc- } \\
\text { cumbed }\end{array}$ & $\begin{array}{l}\text { Days } \\
\text { on } \\
\text { diet }\end{array}$ & $\begin{array}{c}\text { Number } \\
\text { of } \\
\text { rats }\end{array}$ & $\begin{array}{l}\text { Number } \\
\text { suc- } \\
\text { cumbed }\end{array}$ \\
\hline \multirow{2}{*}{4 hours } & $\begin{array}{r}89 \\
\end{array}$ & 0 & 7 & $8 \%$ & 0 \\
\hline & 49 & 0 & 16 & $4 \sigma^{7}$ & 0 \\
\hline \multirow{5}{*}{$4 \frac{3}{4}$ hours } & $12 \%$ & 1 & 11 & $12 \%$ & 3 \\
\hline & $7 \%$ & 3 & 14 & $7 \%$ & 3 \\
\hline & $60^{7}$ & 4 & 16 & $4940^{7}$ & 3 \\
\hline & $11 \%$ & 2 & 22 & $10 \%$ & 3 \\
\hline & $7 \%$ & 6 & 39 & 89 & 4 \\
\hline Totals & 55 & 16 & & 57 & 16 \\
\hline
\end{tabular}


jected to tourniquet for $4 \frac{3}{4}$ hours, one third succumbed to "shock." It made no difference in this series whether the diet had been the normal laboratory diet or whether it was the thiamine-deficient synthetic diet. All animals that died succumbed in less than 36 hours following removal of the tourniquet.

Inasmuch as the transition between no fatalities and approximately 100 per cent fatality occurs in the short interval between approximately $41 / 4$ hours tourniquet time, and approximately 5 to $51 / 2$ hours tourniquet time, and a variation of resistance occurs between ages and between litters, a certain amount of variation in percentage fatality in different experiments with small numbers of animals may be expected. Individual experiments, however, always have been comparisons of sets of litter mates, and show no significant differences in death rates between normally fed animals and those on the deficient diet.

From this series of experiments, it may be concluded that thiamine plays at best a minor rôle in determining resistance to tourniquet shock in rats. One respect in which the thiaminedeficient animals may differ from the normals is in their apparently greater tendency to gastric hemorrhage. Those animals that survive 15 hours or longer seem to show progressively greater gastric hemorrhage. The intestine in almost all cases also contains dark material suggesting partially digested blood. Frequently, the feces of animals going into shock give a positive blood reaction to benzidine reagent. This reaction seems more frequent with the thiamine-deficient animals than with the controls, although it is occasionally also found in the latter following shock. The feces fail to show the reaction before the shock treatment.

\section{SUMMARY}

In rats, a thiamine-deficient diet for various periods (11 to 39 days) had no appreciable influence on the survival rate from shock produced by a tourniquet.

\section{BIBLIOGRAPHY}

1. Govier, W. M., and Greer, C. M., Studies on shock induced by hemorrhage. J. Pharmacol. and Exper. Therap., 1941, 72, 317.

2. Allen, F. M., Physical and toxic factors in shock. Arch. Surg., 1939, 38, 155. 